\title{
Nonlinear analysis of lightweight aggregate concrete columns
}

\author{
Ewelina Kołodziejczyk ${ }^{1}$, Tomasz Waśniewski² \\ ${ }^{1}$ Department of Concrete Structures; Faculty of Civil Engineering, Architecture and Environmental \\ Engineering; Lodz University of Technology; 6 Politechnika Avenue, 90-924 Lodz, Poland; \\ ewelina.kolodziejczyk@p.lodz.pl (D) 0000-0002-3533-4145 \\ ${ }^{2}$ Department of Concrete Structures; Faculty of Civil Engineering, Architecture and Environmental \\ Engineering; Lodz University of Technology; 6 Politechnika Avenue, 90-924 Lodz, Poland; \\ tomasz.wasniewski@p.lodz.pl (DD)0000-0001-7303-4920
}

\begin{abstract}
The paper presents a numerical analysis of deformability and load-bearing capacity of lightweight aggregate concrete (LWAC) elements subjected to bending with axial force. The nonlinear material model of LWAC presented in Eurocode 2 (EC2) was assumed. Several different densities and compressive strengths of concrete were taken into account. The investigations included the comparison of the sectional capacity and the behaviour of slender elements made with normal and lightweight aggregate concrete. It was observed that density-dependent mechanical properties of concrete affect the obtained values of the maximum axial force and the bending moment despite the same mean compressive strength. In every case, the capacity of the RLWAC section was lower than the one of normal weight, which was caused by a linear characteristic of the LWAC. Other important factors were the modulus of elasticity and the ultimate strain of concrete. LWAC with the higher density and the lower ultimate strain gave greater stiffness to slender columns but reduced the cross-sectional capacity. It was concluded that the elastic modulus and the peak strain of LWAC which are applied in columns calculations should be verified experimentally.
\end{abstract}

Keywords: lightweight aggregate concrete, columns, second-order effects

\section{Introduction}

Lightweight aggregate concrete (LWAC) in structural applications is usually identified with its brittle behaviour that is an unfavourable feature in reinforced concrete structures. It is also associated with low elastic modulus, which causes high deformations. All these parameters play an important role in the performance of slender elements subjected to bending with axial force. However, experimental data concerning the problem of second-order effects in LWAC columns is rare in literature and concerns a narrow scope of the issue. In [1] the extensive 
research on the confining effect of transverse reinforcement on the behaviour of reinforced concrete columns is presented. The elements were made with $60 \mathrm{MPa}$ concrete with a fresh density of $1920 \mathrm{~kg} / \mathrm{m}^{3}$. Second-order effects were also analyzed, but the columns had relatively low slenderness $\lambda=21$. Papers [2], [3] show the results of an experimental and numerical analysis of columns with slenderness $\lambda=28$, but they were made with LWC concrete produced with polystyrene foam.

This work aimed to show the behaviour of LWAC columns (cross-section and slender elements) considering different densities and strength of the concrete, and a wide range of slenderness. Numerical analysis of deformability and load-bearing capacity of this kind of elements led in line with Eurocode $2[\mathrm{EC} 2,4]$ requirements, was presented.

\section{Properties of LWAC}

Lightweight aggregate (LWA) and concrete mixture additives available today enable the production of LWAC with a strength comparable to traditional concrete as well as its use in structural applications. The properties of LWAC are specified in the EC2 (section 11) [4]. The code concerns concrete strengths from 17 to $88 \mathrm{MPa}\left(f_{\mathrm{lcm}}\right)$ and allows to estimate its modulus of elasticity $E_{\mathrm{lcm}}$ and ultimate strain $\varepsilon_{\mathrm{lc}}$, which are dependent on its mean compressive strength $f_{\text {lcm }}$ and oven-dry density $\rho$. The density of LWAC considered in the analysis should be between 1000 and $2200 \mathrm{~kg} / \mathrm{m}^{3}$. The nonlinear model of concrete presented in EC2 based on LWAC characteristic was assumed as a starting point for the considerations presented below. Three different levels of the concrete strength were taken (33 MPa, $53 \mathrm{MPa}$, and $78 \mathrm{MPa}$ ). It was needed to define the range of density for each type of concrete to determine the deformation characteristic of the material. There is no information about the correlation between concrete strength and its oven-dry density in EC2. However, it is known that $f_{\text {lcm }}$ tends to increase as the unit weight increases [5], [6]. The effect was presented in the Fig. 1 (on the left).
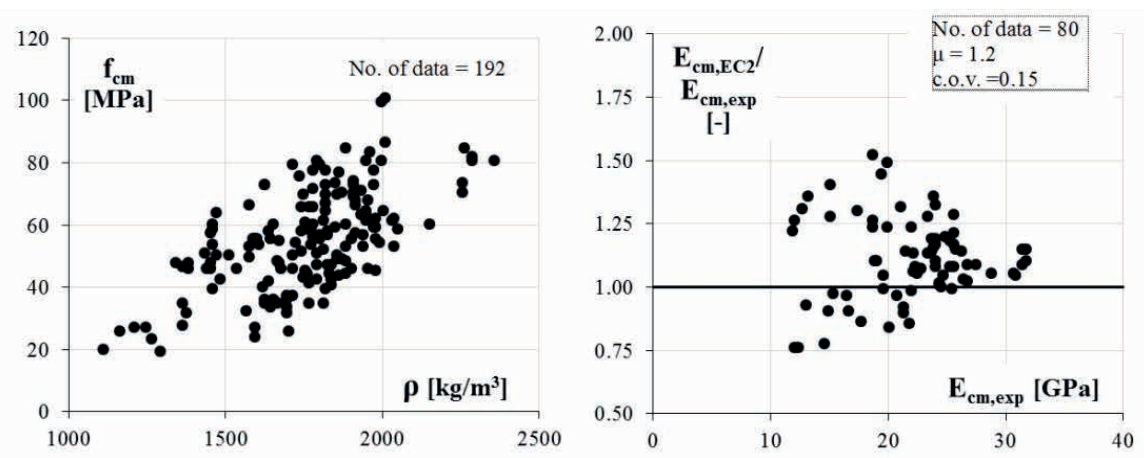

Fig. 1. Mean compressive strength vs oven-dry density of LWAC (on the left). Measured and calculated (EC2) values of modulus of elasticity (on the right). Source: [6]

Based on the experimental data (Fig. 1, on the left), it was determined that the minimum density for concrete with the strength $f_{\mathrm{lcm}}$ of $33 \mathrm{MPa}$ could be taken as $1200 \mathrm{~kg} / \mathrm{m}^{3}$, and $1500 \mathrm{~kg} / \mathrm{m}^{3}$ and $1800 \mathrm{~kg} / \mathrm{m}^{3}$ for $53 \mathrm{MPa}$ and $78 \mathrm{MPa}$ respectively. Material properties of concrete with the strength and the dry concrete density varied from about 20 to $60 \mathrm{MPa}$ and from 1200 to $1600 \mathrm{~kg} / \mathrm{m}^{3}$, respectively are also presented in [7] and [8]. 
Concrete stress-strain EC2 [4] nonlinear models for different concrete strengths defined according to the above assumptions were depicted in Fig. 2. Calculated values of the modulus of elasticity and the strains at the peak stress were presented in Table 1.

Further conclusions presented in [6] indicate, however, that EC2 expressions for modulus of elasticity in most cases of the analyzed data present higher values than the experimental results (Fig. 1, on the right) The differences reach $50 \%$ and the average value is $20 \%$. Similar conclusions can be found in [9].

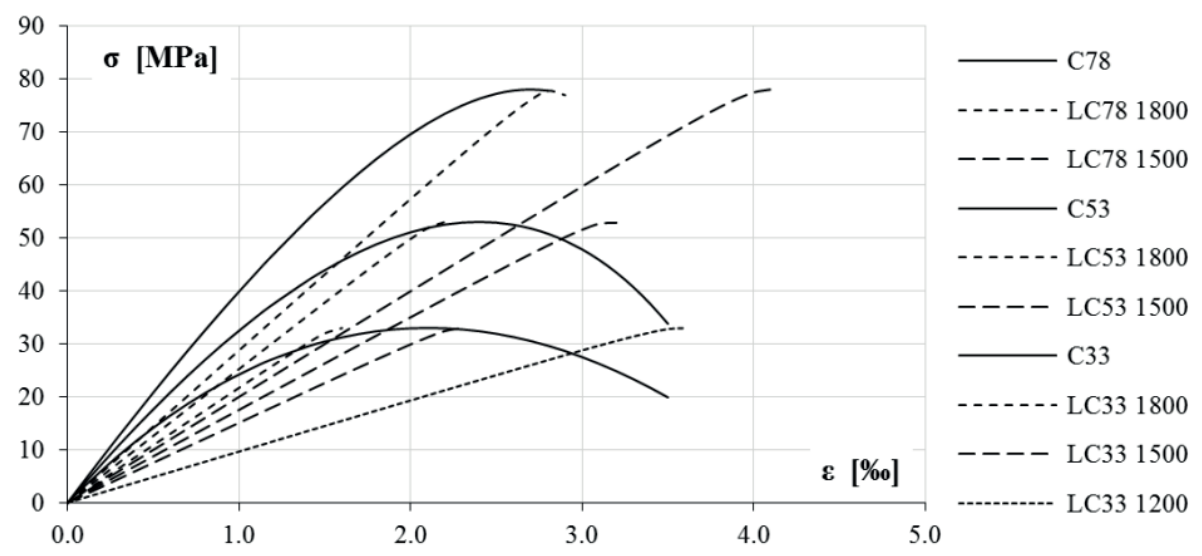

Fig. 2. Concrete stress-strain law. Source: own study

Table 1. Concrete properties

\begin{tabular}{llllll}
\hline \multirow{2}{*}{ Symbol } & Density & $\begin{array}{l}\text { Concrete } \\
\text { strength }\end{array}$ & $\begin{array}{l}\text { Modulus of } \\
\text { elasticity }\end{array}$ & $\begin{array}{l}\text { Strain at the } \\
\text { peak stress }\end{array}$ & $\begin{array}{l}\text { Ultimate } \\
\text { strain }\end{array}$ \\
\cline { 2 - 6 } & $\mathrm{kg} / \mathrm{m}^{3}$ & MPa & GPa & $\%$ o & $\%$ o \\
\hline C33 & 2400 & 33 & 31.0 & 2.10 & 3.50 \\
\hline LC33 1800 & 1800 & 33 & 20.8 & 1.59 & 1.59 \\
\hline LC33 1500 & 1500 & 33 & 14.4 & 2.29 & 2.29 \\
\hline LC33 1200 & 1200 & 33 & 9.2 & 3.58 & 3.58 \\
\hline C53 & 2400 & 53 & 36.0 & 2.40 & 3.50 \\
\hline LC53 2100* & 2100 & 53 & 32.8 & 1.62 & 1.62 \\
\hline LC53 1800 & 1800 & 53 & 24.1 & 2.20 & 2.20 \\
\hline LC53 1500 & 1500 & 53 & 16.7 & 3.17 & 3.17 \\
\hline LC53 1200* & 1200 & 53 & 7.2 & 7.39 & 7.39 \\
\hline C78 & 2400 & 78 & 41.0 & 2.70 & 2.80 \\
\hline LC78 1800 & 1800 & 78 & 27.5 & 2.84 & 2.84 \\
\hline LC78 1500 & 1500 & 78 & 19.1 & 4.09 & 4.09 \\
\hline
\end{tabular}

* only in selected calculations, to show the tendency

Fig. 3 shows experimental results of high-strength lightweight concrete tests presented in [10]. It can be noticed that strain at the $90 \%$ compressive stress for concrete strength of about $80 \mathrm{MPa}$ (Mix 6, 8, 9) can reach about 4\%o. The value corresponds to that for LC78 1500 concrete (Table 1), which was originally not to be included in the analysis (too low density for this level of strength). In the experimental research, the mentioned specimens had concrete density 
$1715 \mathrm{~kg} / \mathrm{m}^{3}, 1764 \mathrm{~kg} / \mathrm{m}^{3}$ and $1886 \mathrm{~kg} / \mathrm{m}^{3}$ and the modules of elasticity $21.6 \mathrm{GPa}, 22.2 \mathrm{GPa}$, and $24.8 \mathrm{GPa}$ respectively.

Due to these inconsistencies, to show the influence of providing material with the stiffness similar to the one obtained in [10], the analysis also included concrete with the strength $f_{\mathrm{lcm}}$ of $78 \mathrm{MPa}$ and the density of $1500 \mathrm{~kg} / \mathrm{m}^{3}$. Moreover, in the selected calculations presented below to depict more general tendency also concrete with the strength $f_{\mathrm{lcm}}$ of $53 \mathrm{MPa}$ and the density of 1200 and $2100 \mathrm{~kg} / \mathrm{m}^{3}$ were considered (Table 1).

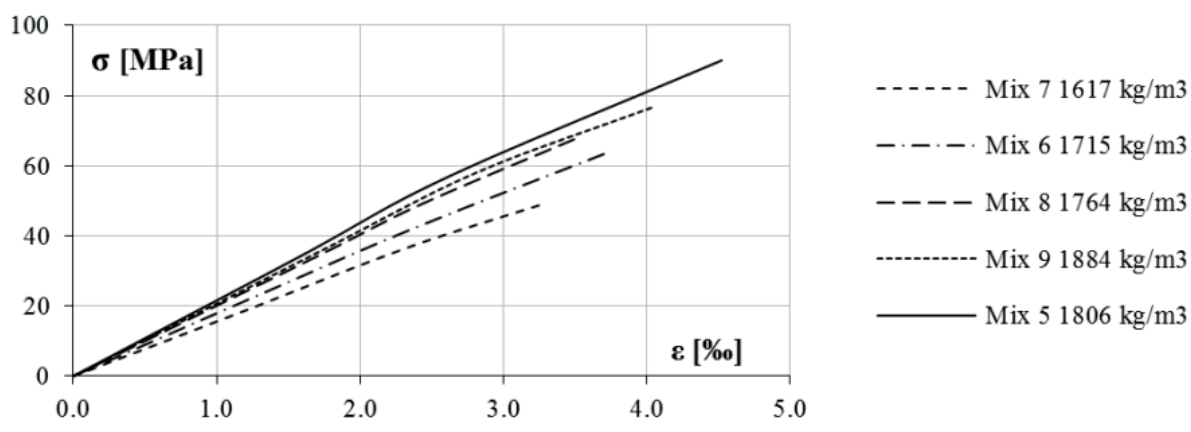

Fig. 3. Experimental stress-strain curves of LWAC at $90 \%$ of the ultimate load. Source: [10]

The presented experimental diagram (Fig. 3) confirms, however, the linear model of the LWAC concrete model established by the authors of EC2 [4]. Doubts related to the determination of the modulus of elasticity and strain at the ultimate stress calculated on its basis. For this reason, it is particularly important to verify the effect of the type of concrete on load-bearing capacity, as well as the differences between different LWAC densities to determine the sensitivity to the possible inaccuracy of the module estimation.

\section{Modelling assumptions}

The parametric study focused on the influence of LWAC material properties acc. to EC2 on the cross-sectional capacity and structural behaviour of reinforced concrete members considering different values of concrete strength, slenderness, and eccentricity of force.

The parametric analysis was conducted in OpenSees, an open-source finite element software for simulating the nonlinear response of structural elements.

ElasticMultiLinear material was used as the stress-strain law for concrete. The nonlinear stress-strain relationship is given by a multi-linear curve that is defined by a set of points which were calculated acc. to EC2 nonlinear model (Fig. 2) for different strengths and densities of concrete. Steel01 bilinear steel material without hardening was applied in relation to the main reinforcement. Concrete tensile strength was not included.

Square cross-section of the column was analyzed as fibre section (Fig. 4, on the left). The section height was $500 \mathrm{~mm}$. It was symmetrically reinforced with $2 \%$ total reinforcement ratio (in selected cases also $0.5 \%$ and $4 \%$ ). The yield strength of steel was assumed as $500 \mathrm{MPa}\left(\varepsilon_{\mathrm{y}}=2.5 \%\right)$. 

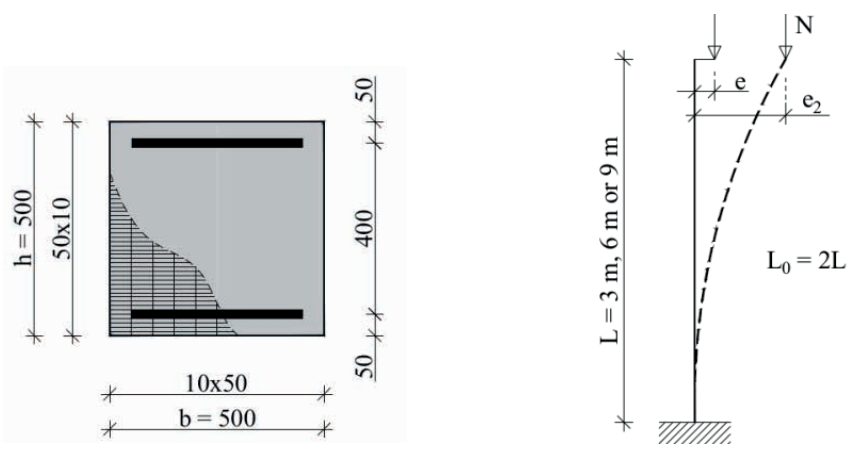

Fig. 4. Fibre cross-section of the element (on the left). Static scheme of the cantilever column (on the right). Source: own study

NonlinearBeamColumn elements modelled reinforced concrete members. Corotational coordinate transformation [11] was used to consider the geometric nonlinearity of the model. The static scheme of a cantilever column under eccentric loading was studied (Fig. 4b). The buckling length $\left(L_{0}=2 L\right)$ was either $6 \mathrm{~m}, 12 \mathrm{~m}$ or $18 \mathrm{~m}$, which corresponds to three slenderness cases $\lambda=42,83$, and 125 . In slender members calculations the two relative eccentricities of the force $e / h=0.05,0.25$ were considered.

\section{Cross-sectional capacity}

The first part of the analysis concerns the load-bearing capacity of the cross-section. There are relative values of axial force $N / b h$, and bending moment $M / b h^{2}$ presented. The results were depicted in the form of $N / b h-M / b h^{2}$ interaction diagrams in relation to different concrete strengths. The ultimate points $\left(M / b h^{2}, N / b h\right)$ were determined as maximum values of internal forces obtained from cross-sectional capacity calculations in the range of permissible strain, for LWAC the values were always reached at ultimate strain.

The results of the analysis for the section made of concrete with the mean compressive strength of $53 \mathrm{MPa}$ were presented in Fig. 5.
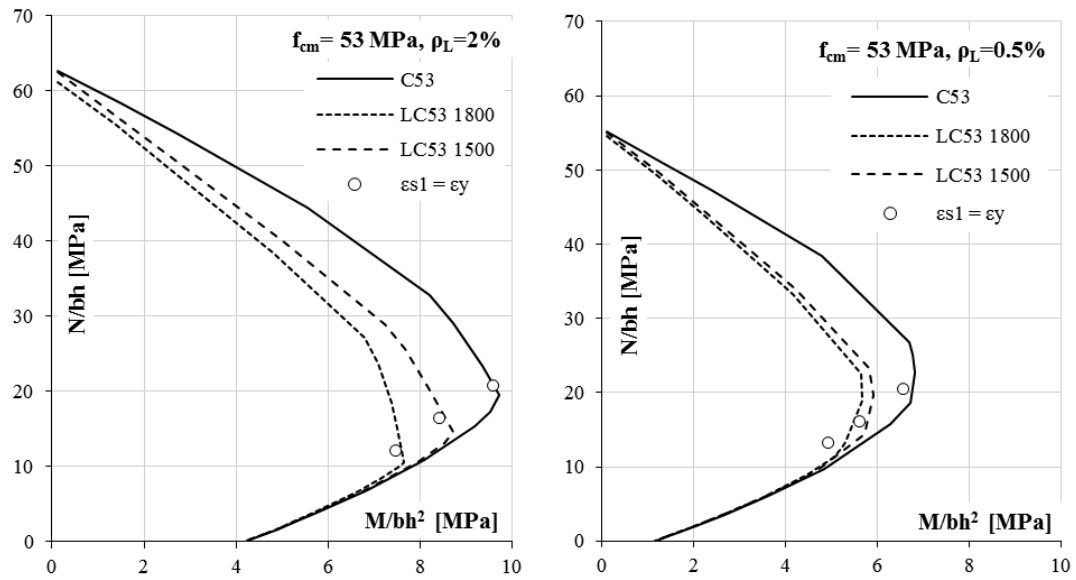

Fig. 5. Interaction diagrams for concrete sections with the strength $f_{\mathrm{lcm}}$ of $53 \mathrm{MPa}$, different densities and total reinforcement ratio of $2 \%$ (on the left) and $0.5 \%$ (on the right). Source: own study 
Two cases (Fig. 5) of total longitudinal reinforcement ratio were analyzed - $2 \%$ (on the left) and $0.5 \%$ (on the right). In each case, three different concrete densities were considered. From both interaction diagrams, we can see that concrete properties connected with its density slightly affect the capacity at axial compression. Small difference, which can be noticed in the case of LC53 1800 concrete at high reinforcement ratio, appears due to the strain achieved in the steel. LC53 1800 concrete has the ultimate strain of 2.2\%o. Therefore, bars do not reach its yield strength, and the force corresponding to the reinforcement is lower than for the other types of concrete. The same situation occurs at low reinforcement ratio, but the share of the steel in the load capacity is minimal, so the effect is not visible.

Another interesting part of diagrams is at small relative axial forces (below $10 \mathrm{MPa}$ ) and high bending moments where all the curves in the diagrams overlap. To explain this behaviour, points corresponding to the first point where the tensile reinforcement reaches its yield strain $\varepsilon_{\mathrm{y}}$ were introduced (Fig. 5). When this point is passed for the least deformable concrete section, the type of concrete does not affect the load capacity. The same internal force values, however, do not mean in this case the same strain in the section, which is connected with different deformability of the considered concrete type.

The most significant difference in the results appears at a relatively high axial force at mid-hight of the diagram. The comparison of the results for the two reinforcement ratios (Fig. 5) indicates that there is more than one reason for varying the maximum forces. The first issue is the character of the concrete model. The nonlinear ascending branch of the model, corresponding to normal weight concrete caused, higher load capacity in comparison to any LWAC concrete, which is characterized by linear behaviour. This effect is visible on both interaction diagrams. Another reason is the influence of the reinforcement. As it can be seen at the small reinforcement ratio (Fig. 5, on the right) results for the two LWAC concretes are close to each other - the steel governs slight part of the load capacity. It changes when we increase the reinforcement ratio (Fig. 5, on the left). In this case, the value of the ultimate strain of LWAC concrete decides about the result. A lower load capacity of the section made with concrete with higher density (LWAC53 1800) and the lower ultimate strain 2.2\%o than the one with the lowest density (LWAC53 1500) and the ultimate strain 3.2\%o can be observed.

The case of mean compressive strength of $33 \mathrm{MPa}$ and $78 \mathrm{MPa}$ was also considered to expand the scope of the observations, (Fig. 6).
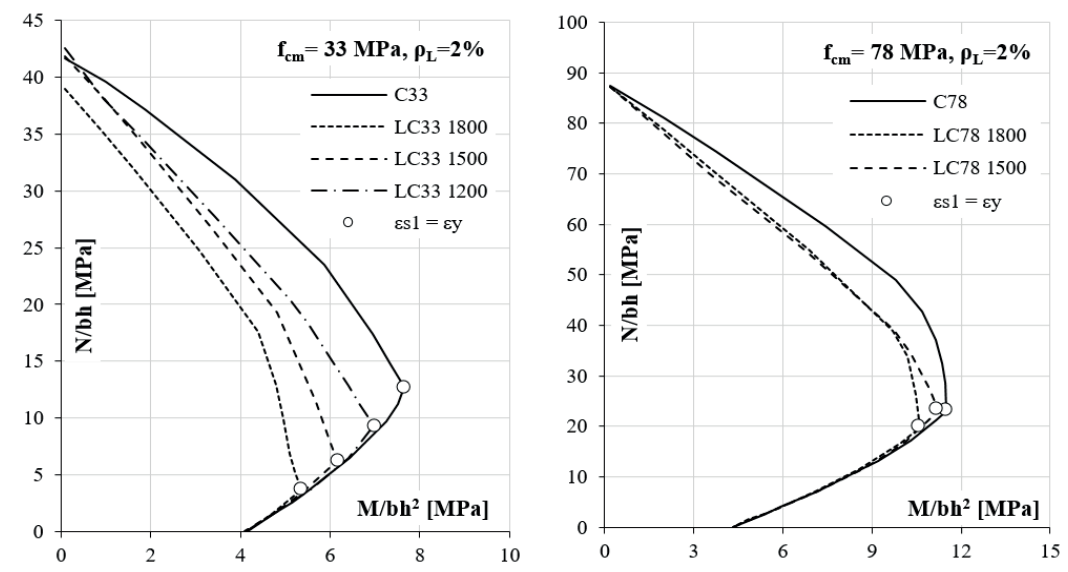

Fig. 6. Interaction diagrams for concrete sections with $2 \%$ total reinforcement ratio for different densities of concrete with the strength $f_{\mathrm{lcm}}$ of $33 \mathrm{MPa}$ (on the left) and $78 \mathrm{MPa}$ (on the right). Source: own study 
The interaction diagrams for $f_{\mathrm{lcm}}$ of $33 \mathrm{MPa}$ (Fig. 6, on the left) show a similar tendency to the previous case $\left(f_{\mathrm{lcm}}=53 \mathrm{MPa}\right)$. The most significant reduction of load-bearing capacity compering to normal weight concrete was obtained for LC33 1800 concrete. First of all, there is an apparent decrease in the maximum axial force. It is due to the very low ultimate strain for this kind of concrete, which is $1.6 \%$. In this situation, the stress in the reinforcement is much lower than its yield strength, which reduces the total sectional capacity not only for axial compression but also in other cases when there is a bending moment as well. Moreover, it can be noticed that the point with maximal moment is very low. For the other LWAC types $\left(1500 \mathrm{~kg} / \mathrm{m}^{3}\right.$ and $\left.1200 \mathrm{~kg} / \mathrm{m}^{3}\right)$ results are more proximate to normal weight concrete as the ultimate strain increases.

In Fig. 6 (on the right), the diagrams for the highest compressive strength were presented. The calculation, the same as in the previous case, was conducted for $2 \%$ reinforcement ratio. In this case, the share of the reinforcement in the capacity is correspondingly lower, so the differences between the two LWAC concrete results are small. The other reason for this outcome is the fact that for all three cases of $78 \mathrm{MPa}$ concrete, the ultimate strain exceeds the yield strain of steel. Besides, because the model of normal weight high strength concrete is closer to the linear than the lower concrete grades, the results of the interaction curves do not vary as much.

To show the more general tendency determined in the analysis, according to the results for concrete with compressive strength of $53 \mathrm{MPa}$, a diagram presented in Fig. 7 was prepared. In this case, the range of concrete density considered in the calculations was extended. The densities of $1200 \mathrm{~kg} / \mathrm{m}^{3}$ and $2100 \mathrm{~kg} / \mathrm{m}^{3}$ were included. Additionally, the $4 \%$ reinforcement ratio was also considered.

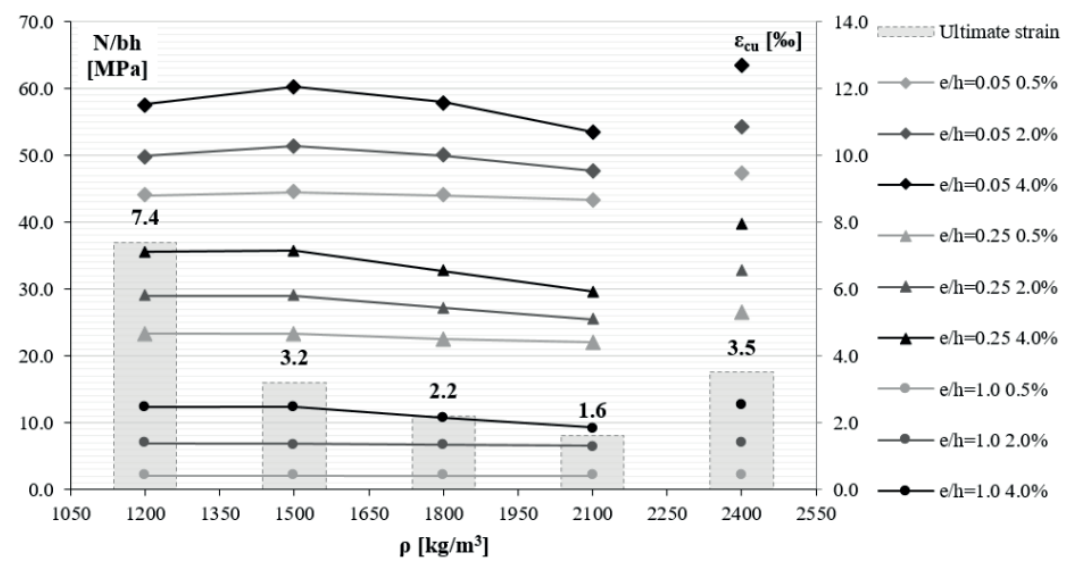

Fig. 7. The influence of concrete density on an ultimate axial force (the left axis) at different eccentricities and reinforcement ratios, the ultimate strain for concrete with the strength $f_{\mathrm{lcm}}$ of $53 \mathrm{MPa}$ for different densities (the block diagram - the right axis). Source: own study

The chart includes two vertical axes. The axis on the left refers to the value of the axial force in individual cases; the axis on the right represents the deformation values shown using a block diagram. Different cases of the reinforcement ratio $(0.5 \%, 2 \%$ and $4 \%)$ and the relative eccentricity of force $e / h(0.05,0.25,1.0)$ were considered. The results for normal weight concrete were given separately on the right $\left(\rho=2400 \mathrm{~kg} / \mathrm{m}^{3}\right)$.

The maximum forces for LWAC in all additional cases are lower than the ones obtained for C53, which confirms previous conclusions. The differences between the results for assumed 
LWAC types are more significant, as the ratio of the reinforcement increases. The extension of the analysis showed another interesting conclusion. The results for the highest eccentricity of the force (close to pure bending) show that at the reinforcement ratio of $4 \%$ a reduction of the maximum axial force for concrete density below $1800 \mathrm{~kg} / \mathrm{m}^{3}$ should be expected, which was not observed in Fig. 5 and Fig. 6. The less ductile behaviour of the strongly reinforced section and the very low ultimate strain caused steel does not to reach the yield strain, and the force was decreased.

In Fig. 7, it can also be noticed that the ultimate strain increases faster when going towards low densities, which results from the method of determining it in EC2, and for $1200 \mathrm{~kg} / \mathrm{m}^{3}$ high value of $7.2 \%$ is obtained. At the same time, in the case of low eccentricity, a decrease in the force is observed. This effect is associated with the strain level in the section and its curvature. As a result of the analysis of the forces in the cross-section, it can be stated that the share of concrete decreases with its stiffness $\left(E_{\mathrm{lcm}}\right)$, the simultaneous increase in strain compensates for this effect by increasing the force in steel with a surplus. This effect reaches its maximum when steel obtains the yield range and then decreases. Hence the loss of the load-bearing capacity for concrete with a density of $1200 \mathrm{~kg} / \mathrm{m}^{3}$.

\section{Column capacity}

In the second part of the parametric study, the authors focused on the second-order response of the elements. The calculations were conducted until the concrete reached its limit strain (in one case in Fig. 8, on the right, the analysis for the highest slenderness was finished at $0.2 \mathrm{~m}$ ). It was limited to the case of $53 \mathrm{MPa}$ compressive strength.

The curves plotting normal force against total bending moment and second-order deflection for rigidly connected cantilever columns are presented below.

The two values of the relative force eccentricity $e / h 0.05$ and 0.25 were considered. Results for the lower force eccentricity and different cases of the column slenderness are presented in Fig. 8.
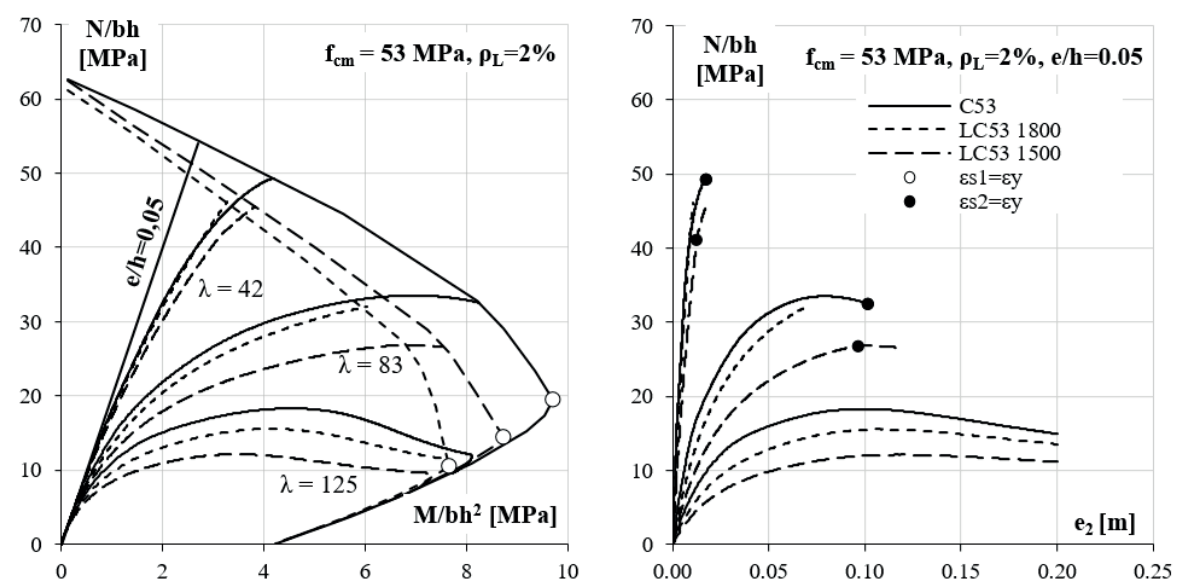

Fig. 8. $\quad N-M$ (on the left) and $N-e_{2}$ (on the right, $e_{2}-$ second-order deflection) relationships for columns made with concrete with the strength $f_{\mathrm{lcm}}$ of $53 \mathrm{MPa}$ at different densities with different slenderness $\lambda$ (relative eccentricity $-e / h=0.05,2 \%$ total reinforcement ratio). Source: own study 
The diagrams (Fig. 8) show that for all concrete types, the influence of second-order effects become more significant with the increase of the slenderness. Interestingly, although in the previous part of the analysis lower density of concrete related to higher sectional capacity, second-order effects have reversed this trend for columns, which is visible in all slenderness cases. For the low slenderness $\lambda=42$, slight values of the displacement were obtained, however still for concrete with the lowest density (LC53 1500) the lowest maximum force was recorded. The same situation was observed for columns with higher slenderness. In all cases, the column stiffness resulting from the modulus of elasticity $E_{\mathrm{lcm}}$ determined the final load capacity. It can be seen in both $\mathrm{N}-e_{2}$ diagrams (Fig. 8 and 9) that for each level of normal force the second-order deflection was the higher, the lower the modulus of elasticity of the concrete that caused the highest second-order moments and the most significant reduction of the maximum normal force in the case of LC53 1500. It is worth adding that LWAC did not exhibit significantly higher maximum deflection; in all cases, it was slightly higher for LC53 1500 and even lower for LC53 1800 compering to C53.
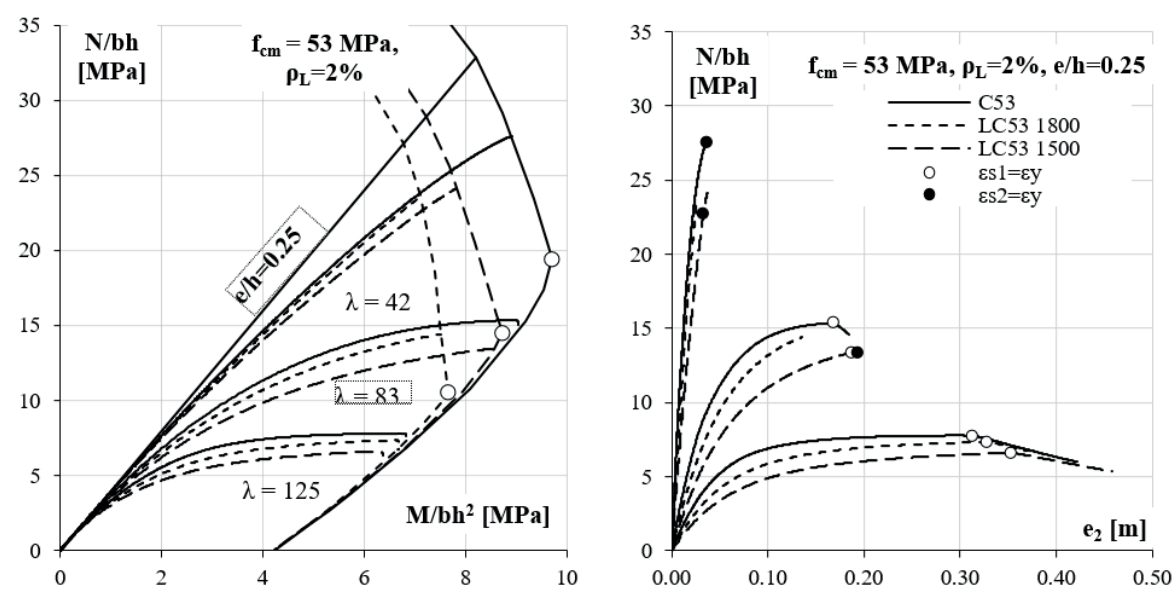

Fig. 9. $\quad M-N$ (on the left) and $N-u$ (on the right, $e_{2}-$ second-order deflection) relationships for columns made with concrete with the strength $f_{\mathrm{lcm}}$ of $53 \mathrm{MPa}$ at different densities with different slenderness $\lambda$ (relative eccentricity $-e / h=0.25,2 \%$ total reinforcement ratio). Source: own study

The case of the higher eccentricity of the force is presented in Fig. 9. This time, when we consider column with the lowest slenderness $(\lambda=42)$ the ultimate normal force was still higher for LC53 1500 (than 1800) but for more slender elements the force for this concrete was the lowest.

\section{Conclusions}

Sensitivity analysis has been conducted to show the influence of a density-dependent mechanical properties of concrete on the load-bearing capacity of sections and slender elements subjected to bending with axial force.

It was revealed that the characteristics of LWAC concrete, its modulus of elasticity and the ultimate strain significantly affect the capacity $(M, N)$ despite the same mean compressive strength. It was determined that lightweight concrete could not be used as a substitute for concrete with normal weight considering only its compressive strength. 
The calculations of the cross-sections showed that in the case of normal weight concrete for all considered compressive strengths (33 MPa, $53 \mathrm{MPa}, 78 \mathrm{MPa}$ ) higher values of the maximum axial force and bending moment were reached comparing to any analyzed LWAC type due to its nonlinear behaviour preceding the maximum stress. Differences in the results for different LWAC types were also observed. The LWAC sections with the lower density of concrete and the higher ultimate strain obtained higher curvature and strain in the reinforcement, which led to the increase in the capacity, in most cases.

The trend observed in the sectional calculations of the LWAC was reversed when geometric nonlinearity was taken into account. Columns made with concrete with the lowest modulus of elasticity (LC53 1500) reached the greatest second-order deflection, which caused the most significant reduction of the maximum normal force and as a consequence, the least result from all analyzed concrete types.

The above conclusions indicate great sensitivity of the obtained results of the load-bearing capacity of this kind of LWAC elements to the assumed density dependant material properties. Therefore, the formulas for the modulus of elasticity [4] referring to LWAC and, as a result, the peak strain, because it has almost linear behaviour, should be considered only as the first approximation, because the modulus is significantly affected by various variables, such as moisture or the type of aggregate. Slender columns should be considered as elements where deflections are of great importance, and in this case, modulus of elasticity should be determined experimentally.

\section{References}

[1] Galeota D., Giammatteo M.M., Gregori A., "Ductility and strength in high-performance, lightweight concrete columns", in 13 ${ }^{\text {th }}$ World Conference on Earthquake Engineering, no. 3414, Vancouver, 2004.

[2] Tawfik M., Elwan S., Seleem H., and Abdelrahman A., "Behavior of lightweight concrete under uniaxial eccentric compressive stresses", International Journal of Engineering Research and Development, vol. 13, no. 9, 2017, pp. 15-27.

[3] Tawfik M., Elwan S., Seleem H., and Abdelrahman A., "Behavior of lightweight concrete columns under eccentric loads (Parametric study)", Al-Azhar University Civil Engineering Research Magazine (CERM), vol. 40, no. 1, 2018, pp. 67-81 .

[4] European Committee for Standardization. EN 1992-1-1, Eurocode 2: Design of concrete structures - Part 1-1 : General rules and rules for buildings, vol. 1. Brussels, 2004.

[5] Lim J. C. and Ozbakkaloglu T., "Stress-strain model for normal- and lightweight concretes under uniaxial and triaxial compression”, Construction and Building Materials, vol. 71, 2014, pp. 492-509.

[6] Galeota D., Giammatteo M.M., Zulli M., "Structural properties of High-Performance Lightweight Concrete", in The First International fib Congress, Osaka, 2002, pp. 247-256.

[7] Suraneni P., Bran Anleu P.C., Flatt R.J., "Factors affecting the strength of structural lightweight aggregate concrete with and without fibres in the $1,200-1,600 \mathrm{~kg} / \mathrm{m}^{3}$ density range", Materials and Structures, vol. 49, 2015, pp. 677-688. https://doi.org/10.1617/s11527-015-0529-2

[8] Rossignolo A., Agnesini M. V.C., Morais J.A., "Properties of high-performance LWAC for precast structures with Brazilian lightweight aggregates”, Cement \& Concrete Composites, vol. 25, 2003, pp. $77-82$.

[9] Costa H., Julio E., and Lourenco J., "Lightweight Aggregate Concrete - Codes Review and Needed Corrections", in Codes in Structural Engineering. Developments and Needs for International Practice, Dubrovnik, 2010. 
[10] Zhang M.-H., Gjorv O.E., "Mechanical Properties of High-Strength Lightweight Concrete", ACI Materials Journal, no. 88, 1991, pp. 240-247.

[11] M. D. Denavit and J. F. Hajjar, Description of geometric nonlinearity for beam-column analysis in OpenSees. Boston, 2013. http://hdl.handle.net/2047/d20003280 
